\title{
Towards Emotional Intelligence behaviour within Virtual Learning Environments: Perceptions of Secondary School Teachers
}

\author{
Felix Donkor \\ School of Sport and Education, Brunel University, UK
}

\begin{abstract}
Although recent research indicates that Emotional Intelligence has important implications for schools, it remains an under-researched construct within the field of education [1]. This is particularly so when it comes to its adoption and use within Virtual Learning Environments (VLEs). Now that we are using VLEs to teach students and we do understand the importance of Emotional Intelligence, it is both imperative and critical to study its efficacy and productivity. In this paper, findings of a research study that examined strategies for supporting the development of students' Emotional Intelligence through the use of a VLE in one secondary school in London are presented. It is argued, based on the analysis of data collected from semi-structured interviews and questionnaires, that the adoption and use of VLEs in schools can offer for teachers, opportunities to develop the Emotional Intelligence of their students and consequently help to maximise the opportunities offered in face-to-face classroom time.
\end{abstract}

\section{Introduction}

In spite of the fact that the adoption of VLE technologies in education has become widespread in the last few years, a review of the extant literature suggests that the VLEs being used in secondary education are not emotionally intelligent. Unlike human instructors, such as teachers, most VLEs are not able to draw upon cues such as students' body language and facial expressions linked to joy, sadness, frustrations or disappointments in order to support and thereby encourage students when they learn within such environments.

Research shows that students who enrol in VLEs tend to demonstrate diminished interest and reduced levels of satisfaction [2]. This behaviour, it can be argued, results from the fact that either the VLEs installed in our academic institutions are not emotionally intelligent or that educators and students have not succeeded in working 'emotional intelligently' within such installations. Indeed, students are more likely to engage with activities within a VLE if they find the VLE (or activities within it) to be responsive to their emotional and academic needs. For, an emotional experience such as enjoyment of learning can direct a student's full attention to a learning task thereby enhancing the student's academic motivation and ability to adopt flexible learning strategies [3]. This in turn requires the use of emotionally and visually stimulating educational materials that can cater for all forms of non-verbal communication within the VLE. Consequently, it has been suggested that when working within a VLE, educators must adopt a multimedia approach that allows maximum transference of information - personal and social information that is intrinsic to learning [4].

The huge surge of interest, policy debate and academic research around the concept of emotions in schools, meanwhile, suggest that it is necessary to pay attention to strategies that can support the development of secondary school students' Emotional Intelligence [5]. Such a need is boosted by arguments from researchers who have posited that students' academic achievement and interpersonal relationships can be impacted positively if they are offered Emotional Intelligence training [6] [7] [8]. Yet, there is no evidence in the literature that points to a framework that can support teachers in the development of their students' Emotional Intelligence through the adoption and use of VLEs. Now that we are using VLEs to teach students and we understand the importance of Emotional Intelligence, it is indeed, both imperative and critical to study the roles VLEs can play in helping to develop our students' Emotional Intelligence. Thus, it is necessary to gain in-depth understanding of how VLEs are being used in schools to support Emotional Intelligence, considering that they increasingly being used in classrooms where more traditional face-toface teaching and learning typically occurred and where arguably there are more affective and group support opportunities. Moreover, increasing attention to aspects such as Emotional intelligence represents a worthy topic for exploration in VLE design and implementation as it highlights some of the issues relating to the adoption and use of modern technologies in schools. A research study of this nature should therefore help in highlighting the technology versus pedagogy debate and hopefully stimulate thinking in that area as well. 


\section{Research Strategies}

\subsection{Stage 1}

10 teachers who are regular users of the focus school's VLE and are responsible for driving its adoption and use within their departments were interviewed as part of the research study in order to access their views about what an emotionally intelligent classroom environment looks or feels like and how the school's VLE may be adapted in order for it to support the development of students' Emotional Intelligence. The interviews were semistructured in nature and were held in the interviewees' classrooms or offices because it was assumed that they would be more comfortable in such environments. Besides, that meant that it was easier for interviewees to access any extra information that they wanted to share, such as information on their computers, planners or classroom displays.

It followed from these preliminary interviews that teachers perceived an emotionally intelligent classroom environment as one which:

- looks or feels flexible, calm and productive

- is alive, interactive and accessible

- is an environment where the child feels safe and is able to take risks

- is a stimulating environment - nothing offensive about it

- is an environment within which collaboration thrives

- is an environment within which every action is underpinned by respect; for students as well as staff.

Furthermore, the teachers suggested that in order to use VLEs to help develop students' Emotional Intelligence there was a need to effectively adopt VLE forums, tools for leaving feedback, emoticons and pictures, as well as strategies for effective communication within the VLE.

\subsection{Stage 2}

This stage of the research study involved a redesign of the school's VLE so that the user interface readily captured some of the suggestions put forward by the teachers. For example, in each virtual classroom a forum was set up and made easily visible for homework support and general discussions relating to academic tasks. The use of video resources was also made a prominent feature within the VLE. In addition to these, teachers were encouraged to use the 'Hand-in' and online testing tools regularly as it offered them opportunities to provide online detailed feedback about students' work. A homework diary was also incorporated into the VLE to encourage the use of the VLE by both teachers and students.
The 10 participating teachers where subsequently asked to trial the tools embedded within the VLE and to note down any observations relating to Emotional Intelligence. To improve upon the internal validity of the data collection process, each teacher was provided with a pro forma which highlighted some of the Emotional Intelligence attributes that they were to look out for. For example, they were asked to note down observations in relation to how the use of forums, videos, online testing and feedback impacted on students' self-confidence, selfawareness, motivation to use the VLE, relationship with others online and in class, empathy and trust. The teachers were then interviewed again in order to assess impacts and to draw causal links where possible. During the interviews, the researcher asked interviewees to talk about their observations in relation to the use of VLE tools trialed. Interviewees were also asked about what ways they think the VLE tools encouraged reflection, self-awareness/selfregulation, empathy, motivation for learning, collaboration and relationship management. They were also asked about how the use of collaborative tools helped in fostering good relationships and positive classroom ambience in subsequent lessons.

In addition to the interviews, questionnaires were used in the research study in order to help dismiss or support the data collected from the interviews. These were anonymously administered via 'survey monkey' so that the chances of respondents providing honest accounts could be increased. The questionnaires comprised open-ended and closed questions in the form of a four-point rating scale. They were sent to the 10 participating teachers by email.

\section{Data Analysis}

To expedite analysis, the open-ended questionnaire data and the interview transcripts were initially coded at the following nodes in Nvivo10:

1. The response contained evidence of how interviewees used videos in the VLE.

2. The response contained evidence of how interviewees used VLE forums.

3. The response contained evidence of how interviewees used feedback.

4. The response contained evidence of how interviewees used test tools.

5. The response gave examples of the impacts of using VLE tools on students' Emotional Intelligence.

6. The response contained evidence of how using VLE tools impact on classroom ambience. 
7. The response raised concerns about VLE adoption in the school.

Exploring the ideas coded at the different nodes and then making connections between them helped in bringing to light the significance of particular comments, observations and emerging themes. The following example illustrates briefly, how the data from the interviews were coded and used to explore emerging themes (pseudonyms used throughout): Mrs Laing, a member of the Senior Leadership Team (SLT) asserted in her interview that Emotional Intelligence in the classroom involves 'having the maturity to make decisions, having the maturity to do things wrong, having the maturity to be independent'. Ms Noble, a music teacher, also remarked that Emotional Intelligence involves the ability 'to respond to situations with a mature attitude', whilst Mr Christian (ICT) described an emotionally intelligent classroom as one where students will be seen maturely discussing what they are supposed to be learning.

It became apparent during the data analysis that the statements above did not fit any of the predetermined categories used for the initial coding. As a result, they were coded at a new node referred to as 'maturity'. The name of the node was chosen to reflect the fact that the word 'maturity' was perceived as an emerging keyword. The surface meaning that may be derived from considering these statements, quite simplistically, is that if a person acts maturely then they are emotionally intelligent. Although such an assertion may be valid it was necessary to explore why the interviewees made those assertions and the underlying meaning - latent meaning. Otherwise, the data analysis would have been a mere scratching of the surface of the data collected. By paying attention to the context of the research and connecting individual statements it was possible to affirm what the interviewees implied. That, in relation to classroom behaviour and relationships, Emotional Intelligence is best perceived on the basis of students' maturity in dealing with situations and with those around them. Even so, it was necessary to then compare and connect these ideas with those generated from other nodes. Undertaking these tasks made it possible for the conclusion to be drawn that developing students' Emotional Intelligence through the use of a VLE requires that students acted maturely - cognitively and emotionally - in a forum, when giving or receiving feedback as well as in their relationships with their teachers and peers.

The responses obtained from the rating scales were analysed separately from the interview and open-ended questionnaire data. Primarily, the rating scale was used as a means of corroborating the responses obtained from the other methods of data collection used. The statements were also used to assess respondents' views about the impact of using VLE tools to support Emotional Intelligence. A four point rating scale was chosen in order to force respondents to show their agreement or disagreement with particular statements. By avoiding the use of neutral or central points, it was hoped that participants would be encouraged to give the statements more thought thereby making their expressed points of view more accurate. Although it may be argued that this approach to data collection can lead to respondents who are genuinely ambiguous about certain dimensions being forced to report inaccurately what they believe, the researcher was convinced that this was the best approach to use given his knowledge of the context of the research study. Besides, all the respondents are regular users of the VLE therefore it was assumed that they would have some strong opinions in relation to the statements used in the rating scale.

\section{Results (Interviews and Open-ended Questionnaire)}

Data obtained from the study showed that when used strategically, VLE tools can impact positively on students' Emotional Intelligence as well as classroom ambience [9]. To explain the basis of this assertion, it is necessary to revisit the classic definition of Emotional Intelligence [10]. That definition posits that an emotionally intelligent person is one who is able to discriminate between the negative and positive effects of emotions as well as use emotional information to guide his or her thinking and behaviour.

Throughout the research study, teachers and students had opportunities to interact with VLE tools which have the capacity to stimulate emotions. Interactions within VLE forums, recording a lesson and embedding it into the VLE, giving and receiving feedback all constitute practices which can heighten emotions amongst users. Where used successfully it was noted that participants of the VLE forum responded to each other politely and in an affirmative manner. As a result, participants reported that positive emotions such as happiness, hope, pride in one's work and abilities, as well as positive outlook were promoted. It also came to light that students were keen on using the VLE forums for information, support and sharing. Teachers who trialed the tools remarked that classroom time was maximized, adding that students' demonstrated great enthusiasm and confidence in their work and were seen to be maturely discussing in class what they were expected to learn.

Indeed, experts in the field of Emotional Intelligence do not refer to the word 'maturity' in their definitions [10] [11]. Nevertheless, in instances where others' behaviors could have aroused negative 
emotions such as anger, frustration, disappointment or distress, it was observed that by acting maturely emotionally and cognitively, students were able to 'discriminate' between the potential causes of positive or negative emotions. Therefore, they were able to ignore unnecessary distractions in the forums and instead concentrated on those activities that were beneficial to them.

Definitions provided in the literature also indicate that developing a person's Emotional Intelligence requires that he or she is engaged in activities that draws their attention to their personality and behaviour. In other words, activities that enables them to be self-aware; to self-regulate their emotions; to develop their social skills; to be motivated to undertake tasks and empathy (SSSME) [10] [11]. This implies that for educators to promote the development of their students' Emotional Intelligence through the adoption and use of a VLE, they must look out for those tools that support their students' SSSME. Participating teachers noted that secondary school students' SSSME can be developed by strategically using a combination of the following VLE tools: videos, forums, and tools for leaving feedback such as the test tools or hand-in folders.

The study showed that three types of videos may be used. First, and at a basic level, teachers and/or their students can upload to their school's VLE appropriate video resources from sources such as YouTube and TeacherTube. The purpose for which such videos may be used might include, preparing students for next lesson, recapping what had been learned in class or supporting students with their homework. Where such resources were carefully chosen, it was observed, that students' confidence, motivation for learning and collaboration with peers were increased thereby leading to the development of emotionally intelligent behaviours such as listening carefully to others' opinions, showing maturity when critiquing others' points of view and/or maturely accepting others' critique during face-to-face classroom time. And this was possible because a) students believed that a video resource that had been recommended by their teacher was likely to impact positively on their learning and b) students believed that their peers may have valid points of view considering that they also had watched the video prior to attending the lesson.

The use of video resources in which the class teacher is featured showed even more promise. As with the other types of video resources that can be used within the VLE, it was noted that using these types of resources led to improved confidence, motivation for learning, resilience, independence and self-regulation - see also [9]. It was brought to light that such video resources facilitated learning beyond the physical classroom environment, by serving as useful aids for parents and guardians to effectively support students with homework. It was apparent from the respondents' points of view that this kind of video resource provides greater advantages compared to the ephemeral nature of face-to-face feedback. Their use is like having personal tuition; they can be referred to as many times as needed [9]; and can be depended upon to promote profound empathy as well as independent learning [12] [13]. Where the video resources were made available to students prior to lessons, the teachers noted, that most students were encouraged to take active roles during face-to-face classroom time as they had very sound background knowledge of what was to be discussed in class. Analyses of the data collected in the study also showed that the quality of classroom discussion and learning can be enhanced and a positive classroom ambience more likely to be achieved if video resources are used in this way. Three of the teachers who were interviewed, noted that such video resources can encourage rapport between teachers and learners, as well as promotes discussions in subsequent face-to-face classroom sessions. Additionally, the videos in which teachers are featured enable students to better recognise and appreciate their teachers' efforts and commitment to their academic success. As a result, one can expect more students to be encouraged to work harder. Furthermore, when teachers take time to prepare such videos for their students, they model profound empathy and thereby, knowingly or unknowingly, encourage their students to demonstrate personal levels of interest and care towards each other [12].

The third type of video resources (those in which students are featured), however, proved to be the most powerful in supporting the development of students' Emotional intelligence. This is in spite of the fact that there is the danger of students competing to be in the spotlight of such videos as suggested by a teacher participant. Apart from offering students similar benefits as the other types of video resources described above, it was observed that this resource offers to students, opportunities to reflect upon their own words and behaviour. Therefore, they are more able to develop self-awareness and self-regulation strategies which undoubtedly, become useful in their dealings with other people.

The study also showed that students could be asked to keep a reflective journal detailing how and what they have learned about themselves as well as the extent to which they have achieved SSSME by drawing upon their experiences in relation to using forums, videos or feedback. The classroom teacher, it was suggested, could subsequently review the reflective journal, offering regular feedback and assistance where needed. Such guidance is likely to create a better learning experience than a VLE in which the classroom teacher is perceived to be distant [2].

It came to light that regular short quizzes designed to boost students' confidence, motivation 
for learning and resilience should be a regular feature on the VLE. These, the teachers argued could be set to auto-mark and provide feedback where possible so as to reduce teacher workload. From a Vygotskian point of view, it is the teacher's responsibility to assess the student's understanding and to identify the point within the Zone of Proximal Development (ZPD) where the learner needs assistance [14] [15]. In traditional classroom environments, teachers support the development of their students' understanding of concepts by posing questions, using examples to illustrate the points they wish to make, encouraging peer discussions, or using tests to assess a student's level of understanding. Attempting to ascertain a student's level of understanding or prior knowledge is thus paramount to the learning process. This is because it provides the impetus for making sound decisions about the next steps that need to be taken into account in the learning process. For example, testing enables teachers and students to gain insights into what learning has taken place. As a result, the ability to distinguish between what is known and what is unknown is enhanced, and so also, is the teacher's (and student's) ability to make accurate decisions about what next to study. Locating the point in the ZPD where intervention is required is thus a very important aspect of the learning process, and one which undoubtedly can be more easily achieved with the use of online testing tools that can be set to auto-mark and to provide feedback [15]. The automated showing of correct answers feature associated with the online testing tools, also enables students to recognise their own mistakes, to learn from them, and to grow in selfconfidence by unobtrusively guiding them to higher levels of attainment. This is achieved when the testing tool highlights what the student has done well and what they need to improve upon. Nevertheless, the current research revealed that it is important for teachers to recognise that being automatic the test tool will not recognise typographic errors so it will mark a pupil's answer wrong when a teacher might mark it correct (or correct a spelling error). This would indeed be very de-motivational and pupils may even 'un-learn' a correct answer. Indeed, this is a very worrying observation in terms of helping to develop students' Emotional Intelligence as well as helping to raise attainment because it suggests that rather than online testing tools helping to stimulate motivation for learning, enjoyment and positive emotions, they can actually lead to disinterest, demotivation, lack of resilience, frustration as well as poor levels of attainment if used incorrectly. Bringing this to light however highlights the dangers associated with using such tools and thereby ensures that teachers are duly informed and aware of such pitfalls when they choose to use such tools within their school's VLE.
Additionally, the current study revealed that it is necessary for teachers to ensure that the short quizzes used within the VLE are closely linked to learning outcomes in order to make it possible for students and teachers to track progress (ZPD). It was noted that it is important for the quizzes to contain appropriate levels of challenge and that assessments are more supportive and useful for students. This is to ensure that students are not easily discouraged to do them. Rather, the gradual increase in the difficulty of tasks to be undertaken, should help them to enjoy the learning experience, improve their understanding, develop their resilience, selfawareness and self-motivation. Furthermore, it was noted that not every learner is able to adapt to independent learning strategies. Therefore, it is necessary to make the learning an interactive process by providing links to VLE forums where students can easily interact with peers, teachers and other learning resources. Over time, it was suggested, that the opportunity to support others and/or collaborate on tasks with others, could lead to the development of profound empathy in both teachers and students, where the participants of the VLE would begin to form positive relationships - within the VLE and transcending to traditional classroom settings. Students would consequently develop a genuine sense of what their peers are feeling, their anxieties, and learning difficulties/limitations as well as peer support mechanisms. They will then begin to understand each other better and consequently would be better equipped to alleviate the emotional barriers to learning that they or their peers may encounter [12].

\section{Results (Rating Scale)}

Table 1 below provides a summary of the responses obtained from the rating scale. Looking at the rating averages it can be seen that only one statement (1.4) had a mean of more than 2 . Considering that the statements were rated from 1 Strongly agree to 4 - Strongly disagree, it may be argued that respondents perception of this item falls between agree and disagree. In other words, on average participants, were a bit unsure of whether or not 'using videos in the VLE help students to selfregulate their emotions'. Even so, a rating average of 2.30 shows a leaning towards agreement with the statement than disagreement of it.

For nominal 4-category questionnaire items such as those used in this case, the use of median instead of mean would seem to some, a more appropriate descriptive statistics to use for analysis. Nevertheless, using the median as a measure of average also indicates that respondents agreed with all the statements, with the exception of statements $(1.5,1.6,1.12$ and 1.13$)$ which they strongly agreed to. Thus, the argument can be made that the teachers 
who responded to this questionnaire uphold the belief that the VLE tools trialed can be depended upon to support the development of secondary school students' Emotional Intelligence. In particular, the data obtained from the rating scale together with the other questionnaire responses and interviews seem to support the proposition that forums, videos, tests and feedback when successfully adapted within VLEs can encourage resilience; foster the formation of good relationships; promote motivation and also aid the development of secondary school students' intrapersonal skills.

\section{Table 1. Summary of Responses Obtained from the Rating Scale Questions}

\begin{tabular}{|c|c|c|c|c|c|}
\hline & $\begin{array}{c}\text { Strongly } \\
\text { agree }\end{array}$ & Agree & Disagree & $\begin{array}{l}\text { Strongly } \\
\text { disagree }\end{array}$ & \begin{tabular}{|l} 
Rating \\
Average
\end{tabular} \\
\hline $\begin{array}{l}1.1 \text { Using videos in the VLE helps to boost } \\
\text { students' confidence }\end{array}$ & $\begin{array}{c}10.0 \% 6 \\
(1)\end{array}$ & $\begin{array}{c}90.0 \% \\
(9)\end{array}$ & $\begin{array}{l}0.0 \% \\
(0)\end{array}$ & $\begin{array}{c}0.0 \% 6 \\
(0)\end{array}$ & 1.90 \\
\hline $\begin{array}{l}1.2 \text { Using videos in the VLE helps students to } \\
\text { be self-aware }\end{array}$ & $\begin{array}{c}30.096 \\
(3)\end{array}$ & $\begin{array}{c}70.0 \% \\
(7)\end{array}$ & $\begin{array}{l}0.0 \% \\
(0)\end{array}$ & $\begin{array}{c}0.0 \% 6 \\
(0)\end{array}$ & 1.70 \\
\hline $\begin{array}{l}\text { 1.3 Using videos in the VLE helps students to } \\
\text { self-regulate their learning }\end{array}$ & $\begin{array}{c}20.096 \\
(2)\end{array}$ & \begin{tabular}{|c|}
$80.0 \%$ \\
$(8)$
\end{tabular} & $\begin{array}{l}0.0 \% 6 \\
(0)\end{array}$ & $\begin{array}{c}0.0 \% \\
(0)\end{array}$ & 1.80 \\
\hline $\begin{array}{l}1.4 \text { Using videos in the VLE helps students to } \\
\text { self-regulate their emotions }\end{array}$ & $\begin{array}{c}0.0 \% 6 \\
(0)\end{array}$ & $\begin{array}{c}70.0 \% \\
(7)\end{array}$ & $\begin{array}{c}30.096 \\
(3)\end{array}$ & $\begin{array}{c}0.09 \% \\
(0)\end{array}$ & 2.30 \\
\hline $\begin{array}{l}1.5 \text { Students behave better when they are } \\
\text { confident }\end{array}$ & $\begin{array}{c}60.0 \% \\
(6)\end{array}$ & $\begin{array}{c}20.096 \\
(2) \\
\end{array}$ & $\begin{array}{c}20.0 \% 6 \\
(2)\end{array}$ & $\begin{array}{l}0.0 \% 6 \\
(0)\end{array}$ & 1.60 \\
\hline $\begin{array}{l}1.6 \text { Low self-esteem can disrupt classroom } \\
\text { ambience }\end{array}$ & $\begin{array}{c}60.0 \% \\
(6)\end{array}$ & $\begin{array}{c}30.096 \\
(3)\end{array}$ & $\begin{array}{c}10.096 \\
(1)\end{array}$ & $\begin{array}{c}0.0 \% 6 \\
(0)\end{array}$ & 1.50 \\
\hline $\begin{array}{l}1.7 \text { Access to videos can encourage students } \\
\text { to support each other }\end{array}$ & $\begin{array}{c}10.096 \\
(1)\end{array}$ & $\begin{array}{c}80.0 \% \\
(8)\end{array}$ & $\begin{array}{c}10.096 \\
(1)\end{array}$ & $\begin{array}{c}0.0 \% 6 \\
(0)\end{array}$ & 2.00 \\
\hline $\begin{array}{l}1.8 \text { The use of videos can lead to effective } \\
\text { communication in the classroom }\end{array}$ & $\begin{array}{c}30.0 \% \\
(3)\end{array}$ & \begin{tabular}{|c|}
$70.0 \%$ \\
$(7)$
\end{tabular} & $\begin{array}{l}0.0 \% \\
10) \\
\end{array}$ & $\begin{array}{c}0.0 \% 6 \\
(0)\end{array}$ & 1.70 \\
\hline 1.9 Forums encourage reflection & $\begin{array}{c}20.096 \\
(2)\end{array}$ & $\begin{array}{c}80.096 \\
(8)\end{array}$ & $\begin{array}{l}0.096 \\
(0)\end{array}$ & $\begin{array}{c}0.096 \\
(0)\end{array}$ & 1.80 \\
\hline $\begin{array}{l}1.10 \text { Forums enable students to support each } \\
\text { other }\end{array}$ & $\begin{array}{c}30.096 \\
(3)\end{array}$ & \begin{tabular}{cc|}
$70.0 \%$ \\
$(7)$
\end{tabular} & $\begin{array}{l}0.0 \% 6 \\
(0)\end{array}$ & $\begin{array}{c}0.0 \% 6 \\
(0)\end{array}$ & 1.70 \\
\hline $\begin{array}{l}1.11 \text { Forums help students to develop better } \\
\text { relationships }\end{array}$ & $\begin{array}{c}10.096 \\
(1)\end{array}$ & $\begin{array}{c}80.0 \% \\
(8)\end{array}$ & $\begin{array}{c}10.096 \\
(1)\end{array}$ & $\begin{array}{c}0.096 \\
(0)\end{array}$ & 2.00 \\
\hline $\begin{array}{l}1.12 \text { Classroom discussions can be enhanced } \\
\text { by online forums }\end{array}$ & $\begin{array}{c}50.0 \% \\
(5)\end{array}$ & $\begin{array}{c}50.0 \% \\
(5)\end{array}$ & $\begin{array}{c}0.0 \% 6 \\
(0)\end{array}$ & $\begin{array}{c}0.0 \% \\
(0)\end{array}$ & 1.50 \\
\hline 1.13 Positive feedback promotes self esteem & $\begin{array}{c}90.0 \% \\
{[9]}\end{array}$ & $\begin{array}{c}10.0 \% \\
(1)\end{array}$ & $\begin{array}{c}0.0 \% 6 \\
(0)\end{array}$ & $\begin{array}{c}0.096 \\
(0)\end{array}$ & 1.10 \\
\hline 1.14 Positive feedback promotes openness & $\begin{array}{c}22.296 \\
(2)\end{array}$ & $\begin{array}{c}77.8 \% \\
(7) \\
\end{array}$ & $\begin{array}{l}0.096 \\
10\end{array}$ & $\begin{array}{c}0.096 \\
(0)\end{array}$ & 1.78 \\
\hline $\begin{array}{l}1.15 \text { Forums, videos, tests and feedback can } \\
\text { encourage resilience }\end{array}$ & $\begin{array}{c}20.096 \\
(2)\end{array}$ & $\begin{array}{c}60.0 \% \\
(6)\end{array}$ & $\begin{array}{c}20.096 \\
(2)\end{array}$ & $\begin{array}{c}0.096 \\
(0)\end{array}$ & 2.00 \\
\hline $\begin{array}{l}1.16 \text { Forums, videos, tests and feedback can } \\
\text { help students to form better relationships. }\end{array}$ & $\begin{array}{c}10.0 \% 6 \\
(1)\end{array}$ & $\begin{array}{c}80.0 \% 6 \\
(8)\end{array}$ & $\begin{array}{c}10.0 \% 6 \\
(1)\end{array}$ & $\begin{array}{c}0.0 \% 6 \\
(0)\end{array}$ & 2.00 \\
\hline
\end{tabular}

\section{Discussion}

The current study indicates that a VLE intended to support secondary school students' Emotional Intelligence must without doubt, include tools (such as videos, forum, online testing tools and tools for leaving feedback) which encourage discussion, peer support, self-awareness, self-regulation, resilience and positive outlook. Developing such Emotional Intelligence skills in students would enable them to become more successful in regulating the negative emotions which may distract them from engaging in effective learning. As a consequence, classroom/learning time can be expected to be maximised as students will be able to collaborate more effectively and therefore are more likely to maturely engage in what they are supposed to be learning. On the one hand, students' learning motivation is likely to be enhanced and a positive classroom ambience attained as students are more likely to see themselves as part of a group. On the other hand, educators will have more opportunities to demonstrate profound empathy as more students take up the responsibility of supporting others.

The VLE must also possess visual and aural stimulation with attention given to detail in presenting content. This is because a poorly planned or presented VLE page - one which is difficult for learners to use - is as off-putting as a poorly presented web page or a poorly planned lesson. This point reinforces observations made by earlier researchers that it is important to ensure that attention to and planning of content are prioritized so that working in the VLE does not end up heightening negative emotions such as frustration or low selfesteem [16]. Unfortunately, this remains a major hurdle for schools, where in most cases, the design and maintenance of the VLE pages have become part of the teacher's role. For those teachers who were born after 1980 (the net generation), this may not be such a big problem as the use of computer technologies may have formed most parts of their daily lives. Even so, it is unrealistic to expect teachers to assume the roles of expert film makers and software designers as part of their professional roles. At best, very few teachers - the enthusiasts will design and use VLEs in exciting and innovative ways. In effect, the rate of VLE adoption and effective use is bound to be slow. On the other hand, designing VLEs should not be the sole responsibility of software designers. Otherwise, we will continuously be entangled in the pedagogy versus technology debate.

The way forward in designing and maintaining successful VLEs which can support our students in the development of Emotional Intelligence characteristics, therefore, is a joint effort of teachers, software developers and students. Whichever way we choose to look at it, one thing is certain, and that is, VLE technologies have come to stay even though their nature and scope may change over time. Therefore, it is important that we continue to examine ways by which important and yet underexamined constructs relating to classroom practices such as Emotional Intelligence are adapted within them. Otherwise, apart from a possible decline in academic achievements, our students are likely to be trapped into emotionally unintelligent behaviours such as cyber-bullying, sarcasm and narcissism when they communicate with others online. And this could be even more dangerous if such behaviour transcends to a physical classroom.

\section{References}

[1] Zwozdiak-Myers, P. (2012). The teacher's reflective practice handbook: becoming an extended professional through capturing evidence-informed practice. Abingdon, Oxon: Routledge. 
[2] Hove, M.C. and Corcoran, K.J. (2008). Educational Technologies: Impact on Learning and Frustration. Teaching of Psychology, 35(2), pp. 121-125

[3] Balaam, M., Fitzpatrick, G., Good, J., and Luckin, R., (2010). "Exploring affective technologies for the classroom with the subtle stone", Classroom Technologies, April $10-15$, pp. 1623-1632.

[4] Cooper, B. (2006) - The significance of affect in multi-modal communication: lessons for on-line learning, The International Journal of Interactive Technology and Smart Education, Special issue.

[5] Gillies, V. (2011). Social and emotional pedagogies: critiquing the new orthodoxy of emotion in classroom behaviour management. British Journal of Sociology of Education, 32(2), pp. 185-202.

[6] Parker, J.D.A., Crequesr, R.E., Barnhart, D.L., Harris, J.I., Majeski, S.A., Wood, L.M., Bond, B.J. and Hogan, M.J. (2004). Academic achievement in high school: does emotional intelligence matter? Personality \& Individual Differences, 37(7), pp. 1321-1330.

[7] Petrides, K.V., Frederickson, N. and Furnham, A. (2003). The role of trait emotional intelligence in academic performance and deviant behavior at school. Personality \& Individual Differences, 36(2), pp. 277.

[8] Goleman, D. (2008). The Secret to Success. Education Digest, 74(4), pp. 8-9.

[9] Donkor, F., (2013). Using VLEs to Support Emotional Intelligence: A Secondary School Perspective, Proceedings of $10^{\text {th }}$ IFIP World Conference on Computers in Education, (Ed. Reynolds, N. and Webb, M.), July 2-5, Torun, Poland, pp. 36-44.

[10] Salovey, P. and Mayer J. D. (1990). Emotional intelligence, Imagination, Cognition, and Personality,9, pp. 185-211.

[11] Goleman, D. (1995). Emotional intelligence: Why it can matter more than $I Q$. London: Bloomsbury

[12] Cooper, B., (2010). In search of profound empathy in learning relationships: understanding the mathematics of moral learning environments, Journal of Moral Education, 39(1), pp. 79-99.

[13] Coffield, F., Moseley, D., Hall, E. and Ecclestone, K. (2004). Learning Styles and Pedagogy in post-16 learning: a systematic and critical review. Learning and Skills Research Centre, London. Available from: http://sxills.nl/lerenlerennu/bronnen/Learning [Accessed: 11th March, 2014]

[14] Vygotsky, L.S. (1978). Mind in society: the development of higher psychological processes, Cambridge, Mass, Harvard University Press.
[15] Ahmed, A. and Pollitt, A. (2010). The Support Model for interactive assessment, Assessment in Education: Principles, Policy \& Practice, 17(2), pp. 133-167.

[16] Crook, C. and Cluley, R. (2009). The teaching voice on the learning platform: seeking classroom climates within a virtual learning environment. Learning, Media and Technology, 34(3), pp. 199-213. 